\title{
Framework for Improving Construction Health and Safety on Ghanaian Construction Sites
}

\author{
D. Osei-Asibey*, J. Ayarkwa, A. Acheampong, E. Adinyira, P. Amoah \\ Department of Construction Technology and Management, Kwame Nkrumah University of Science and Technology (KNUST), \\ Kumasi, Ghana \\ Email: *dicksonoseiasibey@gmail.com, ayarkwajosh@yahoo.com, rasadii@yahoo.com, \\ achielex@yahoo.com,amoahp@gmail.com
}

How to cite this paper: Osei-Asibey, D., Ayarkwa, J., Acheampong, A., Adinyira, E. and Amoah, P. (2021) Framework for Improving Construction Health and Safety on Ghanaian Construction Sites. Journal of Building Construction and Planning Research, 9, 115-137.

https://doi.org/10.4236/jbcpr.2021.92009

Received: April 1, 2021

Accepted: June 1, 2021

Published: June 4, 2021

Copyright $\odot 2021$ by author(s) and Scientific Research Publishing Inc. This work is licensed under the Creative Commons Attribution International License (CC BY 4.0).

http://creativecommons.org/licenses/by/4.0/

(c) (i) Open Access

\begin{abstract}
The enormity of the problem of construction accidents and hazards in the Ghanaian construction industry (GCI) calls for the need to engage in relevant research to equip stakeholders with the required knowledge to improve construction health and safety (CHS) and reduce site accidents and hazards. The complexity of the problem of accident causation explains a large number of conceptual models developed to aid the understanding of the dynamics involved in CHS. This paper involved a qualitative study to identify causes of accidents and hazards in the GCI and underlying issues requiring remedying and also a desk study to review Health and Safety related theories and concepts from extant literature to explain and contribute to the improvement of CHS. The paper contributes to the use of theories to advance studies on improving health and safety at construction sites, especially in developing countries like Ghana, where such studies have so far attracted little attention. The framework may enable construction stakeholders to easily identify problem areas on site and apply required improvement measures to create a healthier and safer construction site. The findings may provide useful knowledge to improve CHS and reduce site accidents and hazards, and also provide a multi-theory approach for understanding the dynamics of the complexity of the problems involved in CHS.
\end{abstract}

\section{Keywords}

Framework, Health, Safety, Theories, Accidents, Hazards, Construction, Site

\section{Introduction}

The intrinsic properties that characterize the construction industry contribute largely to accidents and hazards and fatalities on construction sites [1]. The 
enormity of the problem of construction accidents and hazards in the Ghanaian construction industry calls for the need to engage in relevant research to equip stakeholders with the required knowledge to improve construction health and safety (CHS) and reduce site accidents and hazards.

The construction industry in Ghana, as in other parts of the world, is huge and a crucial segment in economic development. The importance of construction industry as one of the top contributors of the Ghanaian economy, cannot be over-emphasized, especially as the country is one of the most active economically in West Africa. The Gross Domestic Product (GDP) of the Ghanaian construction industry grew from GHS12,183 million in 2014 to GHS21,013 million in 2019 [2], and was expected to grow to $7.4 \%$ in 2020 [3]. The industry is dominated by $67.2 \%$ unskilled labor force and $24.8 \%$ semi-skilled labor force, while $8 \%$ are considered highly skilled [4]. Like other developing countries, the Ghanaian construction industry highly depends on the labor force. Given the high cost of adopting equipment intensive methods for construction, and the fact that the labor force is readily available at lower cost in Ghana, the labor-intensive approach is often preferred by contractors. The stakeholders in the Ghanaian construction industry include clients, consultants, suppliers, statutory authorities, contractors, and community or traditional authorities.

\subsection{Accidents and Hazards}

Accidents have been defined as any happening of an undesirable event characterized by a short, sudden and unexpected event resulting from the activity of man other than natural consequences directly or indirectly [5]. Accidents and hazards have also been defined in various forms, but the simplest definition by Stranks [6] is that accidents and hazards are uncontrollable occurrences which result in injury or damage. In fact, construction work is sometimes described as non-repetitive and ergonomically dangerous due to the lifting of heavy objects and dangerous chemicals. These often result in high record of accidents, hazards and injuries [7].

What distinguishes occupational accident from other accidents is the fact that they happen in a working life context and that the main consequences are limited to injuries on the workers involved. Accidents cannot completely be prevented and therefore plans must be put in place to meet the unexpected. Legal requirements are the good safety program to prevent accidents [8]. In Ghana, the Ministry of Employment and Labor Relations employs 97 safety inspectors, which equals one inspector per 136,371 workers [2], compared with International Labor Organization's (ILO) recommendation of one inspector per 40,000 workers in less developed countries [9]. Labor inspectors are usually criticized for being insufficient to enforce compliance, poorly trained and lacking resources to respond to violations effectively.

The trend in recent times is that achieving accident-free workplaces is the concern of many countries [10]. In the global context, workplace injury rate (injuries per 100,000 workers), accident frequency rate (accidents per 1 million 
man-hours), accident severity rate (loss of man-days per 1million man-hours) and occupational deceased incidence (occupational deceased per 100,000 workers) can be taken as important factors to determine the effectiveness of local safety standards [10].

On the Ghanaian situation, the percentage of construction industry to the national indicators of occupational injury is $4.7 \%$. The accident frequency rate of the construction industry is 65 compared with the national indicator of 43 , a percentage of $151 \%$ higher [11]. Again, Ghana Statistical Service, GSS [11] provided statistics of construction indicators of occupational injury in 2015. The deceased incidence rate recorded in Ghana was 63 in the year 2015. However, the construction industry recorded 86 in the same year. Thus, the Ghanaian construction industry (GCI) recorded an increase of $137 \%$ over the national figure indicating a very high risk of the accident in the industry. The severity rate of occupational injury nation-wide was 418 , which is higher than the 346 recorded in the GCI in 2015. The low severity rate in the construction industry compared with the national indicator resulted in fewer days lost in 2015 of 9 compared with 16 nationwide [11].

According to the 2015 occupational injury report of the GCI, accidents are highly reported and therefore records available do not represent the entire picture [12]. Some accidents may not be reported due to various reasons, such as geographical location, communication difficulties, governmental interference, cultural barriers etc. [13].

Accidents and hazards are in various forms and have been grouped in the construction industry [14]. Ramachandran's [15] classification of construction accidents and hazards are according to the following three forms: 1 ) the severity of the injury, 2) the nature of injury and 3) the cause of accidents and hazards. According to Ramachandran [15], the severity of injury classification of accidents and hazards has a sub-division classification as major accidents and hazards, minor accidents and hazards or accidents and hazard. Moreover, accidents and hazards classified according to the nature of injury, can be further subdivided into death, temporary disablement, permanent disablement, and partial disablement accidents and hazards. The third category of accidents and hazards, according to Ramachandran [12], relates to the construction activities that lead to the cause of accidents and hazards. The causes of such accidents and hazards, according to Ramachandran [15], may be the consequence of equipment fault, trench collapse, crane failure, construction site falls, among others. Any construction accidents and hazards may belong to any one or more of the above accidents and hazards classifications.

The most occurring accidents and hazards at the construction sites are caused by crane, scaffolding, trench collapses etc. [16] [17]. In all the forms of accidents and hazards, site falls have been recorded as the most frequently occurring on construction sites, with 300 deaths out of 1000 deaths of construction accidents and hazards relating to site falls [18] [19]. It is therefore important for manage- 
ment of construction organizations to provide proper measures to prevent such accidents and hazards. It must be emphasized that each of these forms of accidents and hazards can be avoided through efficient and effective health and safety measures.

\subsection{Causes of Construction Accidents and Hazards}

It is essential for the successful prevention of accidents to understand their causes [20]. Health and safety can effectively be managed in construction when factors that play key roles in the causation of accidents and hazards are clearly understood [6]. Moreover, accidents and hazards prevention techniques could also be developed by understanding the major causes of accidents and hazards on site. Causes of construction accidents and hazards according to Health and Safety Executive (HSE) [16], are summarized into four major categories as shown in Figure 1.

Worker and work team factors relate to the communication challenges, individual's actions, and capabilities, according to European Statistics on Accidents at Work (ESAW) [21]. The workplace causes also relate to welfare facilities, inadequacy of working space, and ground conditions including undulated and precarious terrain or loose grounds. The environmental conditions, also include dusty working conditions, poor lighting and sunlight reflection on concrete and poor weather [21].

Materials and equipment relating to causes of accidents and hazards may result from the changes in the quality of construction materials, mode of the supply, availability and adequacy of materials, lack of information regarding the usage of materials and equipment and the use of contaminated materials. The exposure of the construction operatives to these causes of accidents and hazards has adverse effect on them. Manufacturers and suppliers are expected to provide adequate information on the usage of materials and equipment on site. Moreover, suppliers are expected not to distribute faulty and obsolete equipment and

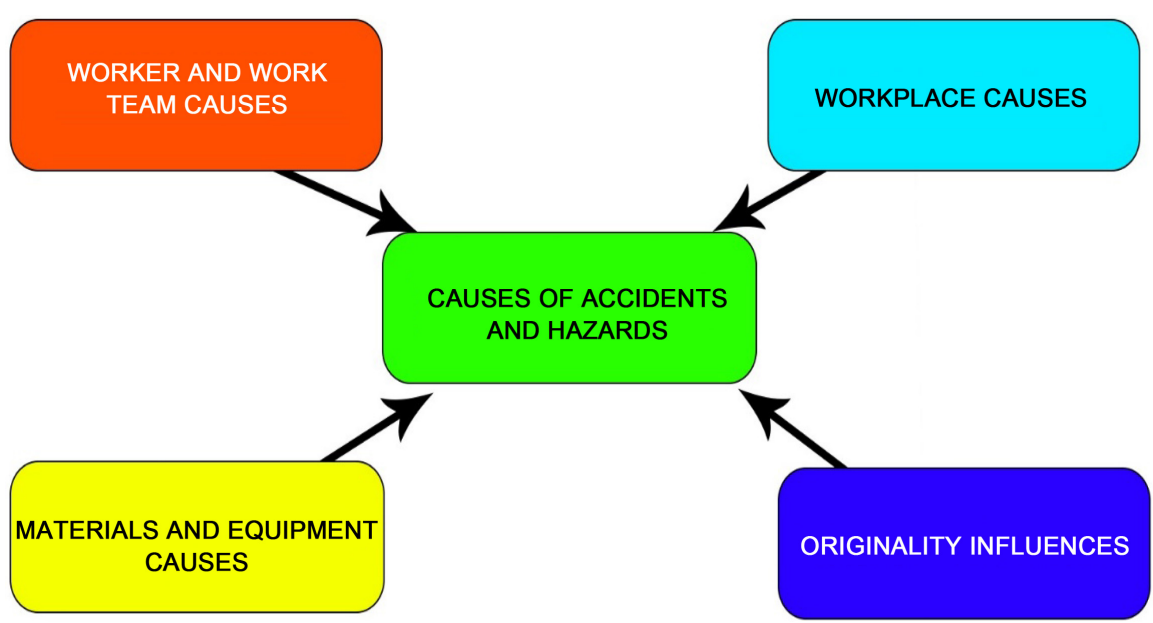

Figure 1. Major categories of causes of construction accidents and hazards. Construct: authors. 
expired materials for construction works. The employers must ensure adequate and availability of materials and equipment.

Accidents and hazards relating to the works design and project management techniques are considered as the fundamental causes of accidents and hazards [22]. In fact, inaccurate designs and poor construction supervision can cause a newly constructed structure to fail and collapse, which can cause accidents and hazards. Likewise, confusion between consultants and contractors over ownership authority of the project can result in different instructions to workers, which can lead to poor workmanship and result in accidents and hazards on sites. Moreover, unplanned sites often result in insufficient working space. The unavailability of working space restricts the allocation of working area for storage, footpath, transport route and workshop placement. In such instances, heavy duty vehicles can knock workers down; also, there is the possibility of double handling of materials which could result in accidents and hazards [23]. Abdelhamid and Everett [24] also identified three main causes of construction accidents and hazards viz.: workers unsafe act, workers response to unsafe conditions, and unsafe conditions. They emphasized that unsafe conditions such as open sided floors, defective ladders, protruding ends of reinforcements, improperly constructed scaffolds, unprotected explosive materials, and exposed trenches cause great death and injuries to workers and pedestrians. Moreover, a worker's unsafe act also causes accidents and hazards irrespective of the working condition. Very often, workers on site lack the right attitude towards safety, with many workers failing to take responsibility for ensuring personal safety on site. For instance, workers disregarding established safety precautions such as ignoring the usage of personal protective equipment can lead to severe accidents and hazards on site.

Huang and Hinze [18] also emphasized that the unavailability of protection equipment and improper use of safety equipment contributes greatly to accidents and hazards on construction sites. Moreover, failure of workers to show positive safety attitudes causes accidents and hazards on site [25]. It is therefore important for workers on site to comply with safety regulations and provisions. Wong et al. [17] also identified improper equipment and working platform, wrong safety attitude and inadequate housekeeping as the underlying causes of construction accidents and hazards. It is obvious that the poor usage of equipment and bad attitude towards safety, expose the workers and even pedestrians to accidents, hazards and injuries. Poor supervision and monitoring, and improper procedures and safety guidelines can also contribute to accidents and hazards on site.

In the Ghanaian construction industry, according to Laryea and Sarfo [26], the major reasons for the poor state of health and safety at construction sites include lack of strong institutional framework for regulating construction activities, poor enforcement of health and safety policies and procedures, and the lack of placing high priority on construction health and safety. Eyiah et al. [27] also 
suggested that legal and regulatory challenges, among other factors, contribute to low occupational health and safety performance in Ghana.

In summary, the review of causes of accidents and hazards reveals seven (7) basic factors that require improvements by all stakeholders: 1) Bad Attitudes and Behavior; 2) Lack of Competency and Skills; 3) Working Environment; 4) Construction health and safety knowledge; 5) Work System; 6) Interrelationship between stakeholders in ensuring construction health and safety; and 7) Sanctions, Motivations and Compensation. The purpose of this research is to identify, from the perspective of stakeholders of the Ghanaian construction industry, the issues on site requiring improvement in order to reduce construction accidents and hazards.

\section{Research Methodology}

To develop a framework for improving construction health and safety at site required the identification of areas requiring improvement from underlying causes of accidents and hazards on site. It also required the identification of relevant health and safety theories that could explain and contribute to the improvement of construction health and safety. A qualitative study was undertaken to identify causes of accidents and hazards on Ghanaian construction sites in order to identify the issues requiring improvement. A review of Theories of Health and Safety was also conducted to identify relevant theories that could contribute to the understanding of the dynamics of the issues of construction health and safety and their improvement on site.

The qualitative approach was chosen because it reveals existing knowledge through questions and answers, and its results are easily accessible to interpret [28]. According to Gay et al. [29], researchers are able to gather adequate information by acting as an interviewer who forms part of the data collection process when qualitative approach is adopted, to give a large quantity of in-depth information. In-depth interviews using semi-structured open-ended questions were conducted through face to face interviews with key officers and professionals of the major stakeholder groups: Contractors (D1K1 and A1B1), Consultant, Supplier/Manufacturers and Construction Workers. The professionals in large and experienced construction firms (contractors) in the class and categories D1K1 and A1B1, with at least 5 years working experience, were selected because these are likely to make the effort to comply with health and safety requirements. The other three stakeholder groups were also selected because of their active involvement in operations at construction sites. For example, the suppliers were included because they are expected to supply equipment and tool in good working conditions, and provide adequate and right information relating to the usage of materials and equipment for site safety. Seven interviewees each from the Contractors, Consultants, Construction Workers and Suppliers/Manufacturers groups participated in the interview, resulting in a total of twenty-eight (28) participants. 
Purposive sampling technique was adopted for the selection of interview participants to have in-depth information on the phenomenon under study. The adoption of the approach enabled persons familiar with construction health and safety principles and management to be interviewed. Persons of management level who are part of the decision-making within their organizations were the interviewees. Therefore, the views of the interviewees were highly reliable and dependable. Table 1 shows the summary of the background of the interviewees, and Figure 2 shows the research flow of the study.

Table 1. Summary of background of interviewees.

\begin{tabular}{|c|c|c|c|}
\hline Code A. & Status of Contractors & Type of Firm & Years of Experience \\
\hline CR1 & Senior Quantity Surveyor & $\mathrm{A} 1 \mathrm{~B} 1$ & $\begin{array}{l}12 \text { years as member of } \\
\text { Ghana Institution of } \\
\text { Surveyors (GhIS) }\end{array}$ \\
\hline CR2 & Senior Engineer & $\mathrm{A} 1 \mathrm{~B} 1$ & $\begin{array}{l}15 \text { years as member of } \\
\text { Ghana Institution of } \\
\text { Engineering (GhIE) }\end{array}$ \\
\hline CR3 & Project Engineer & $\mathrm{D} 1 \mathrm{~K} 1$ & $\begin{array}{l}22 \text { years as Architect and } \\
\text { member of Ghana Institute } \\
\text { of Architects (GIA) }\end{array}$ \\
\hline CR4 & Site Manager & $\mathrm{D} 1 \mathrm{~K} 1$ & $\begin{array}{l}15 \text { years holder of BSc } \\
\text { Building Technology }\end{array}$ \\
\hline CR5 & Site Manager & $\mathrm{A} 1 \mathrm{~B} 1$ & $\begin{array}{l}16 \text { years holder of BSc Civil } \\
\text { Engineering }\end{array}$ \\
\hline CR6 & Project Manager & $\mathrm{A} 1 \mathrm{~B} 1$ & 18 years as member of GhIE \\
\hline CR7 & Senior Quantity Surveyor & $\mathrm{D} 1 \mathrm{~K} 1$ & 14 years as member of GhIS \\
\hline B. & Status of Consultants & & \\
\hline CT1 & Senior Quantity Surveyor & QS firm & 14 years as member of GhIS \\
\hline CT2 & Senior Architect & $\begin{array}{l}\text { Architectural } \\
\text { Firm }\end{array}$ & 15 years as member of GIA \\
\hline CT3 & Senior Architect & $\begin{array}{l}\text { QS and Arch. } \\
\text { Firm }\end{array}$ & $\begin{array}{l}22 \text { years as Architect and } \\
\text { member of GIA }\end{array}$ \\
\hline CT4 & Senior Quantity Surveyor & QS firm & 15 years member of GhIS \\
\hline CT5 & Architect & $\begin{array}{l}\text { Architectural } \\
\text { Firm }\end{array}$ & 10 years as member of GIA \\
\hline CT6 & Senior Engineer & $\begin{array}{l}\text { Civil and } \\
\text { Structural } \\
\text { Engineering } \\
\text { Firm }\end{array}$ & 15 years as member of GHIE \\
\hline CT7 & Senior Engineer & $\begin{array}{l}\text { Civil and } \\
\text { Structural } \\
\text { Engineering } \\
\text { Firm }\end{array}$ & 14 years as member of GHIE \\
\hline CW1 & $\begin{array}{l}\text { General Foreman } \\
\text { (Carpenter) }\end{array}$ & $\mathrm{A} 1 \mathrm{~B} 1$ & $\begin{array}{l}20 \text { years Construction } \\
\text { Technician (CTC2) }\end{array}$ \\
\hline
\end{tabular}




\section{Continued}

\begin{tabular}{|c|c|c|c|}
\hline CW2 & Mason Foreman & D1K1 & $\begin{array}{l}15 \text { years member as } \\
\text { Construction site worker }\end{array}$ \\
\hline CW3 & General Foreman (Mason) & A1B1 & $\begin{array}{l}17 \text { years as Construction site } \\
\text { worker (Technical School } \\
\text { Graduate) }\end{array}$ \\
\hline C. & Construction Workers Cont'd & & \\
\hline CW4 & Labourer Foreman & A1B1 & $\begin{array}{l}15 \text { years as Construction Site } \\
\text { Worker }\end{array}$ \\
\hline CW5 & Steel bender Foreman & D1K1 & 18 years as site worker \\
\hline CW6 & Carpenter Foreman & $\mathrm{A} 1 \mathrm{~B} 1$ & $\begin{array}{l}11 \text { years Construction } \\
\text { Technician (CTC2) }\end{array}$ \\
\hline CW7 & Labourer Foreman & $\mathrm{D} 1 \mathrm{~K} 1$ & $\begin{array}{l}14 \text { years as Construction Site } \\
\text { Worker }\end{array}$ \\
\hline D. & $\begin{array}{l}\text { No. of Depots Owned by } \\
\text { Suppliers/Manufacturers }\end{array}$ & \multicolumn{2}{|c|}{ Activities } \\
\hline MS1 & More than two depots & \multicolumn{2}{|c|}{ Manufacturer and Supplier of cement } \\
\hline MS2 & More than three depots & \multicolumn{2}{|c|}{ Supply of iron rods and cement } \\
\hline MS3 & Four depots & \multicolumn{2}{|c|}{ Supply of tiles Only } \\
\hline MS4 & Five depots & \multicolumn{2}{|c|}{ Supply of iron rods and cement } \\
\hline MS5 & More than 3 depots & \multicolumn{2}{|c|}{ Manufacturer and Supplier of roofing sheets } \\
\hline MS6 & More than 3 depots & \multicolumn{2}{|c|}{ Manufacturer and Supplier of roofing sheets } \\
\hline MS7 & More than 3 depots & \multicolumn{2}{|c|}{ Manufacturer blocks and concrete products } \\
\hline
\end{tabular}

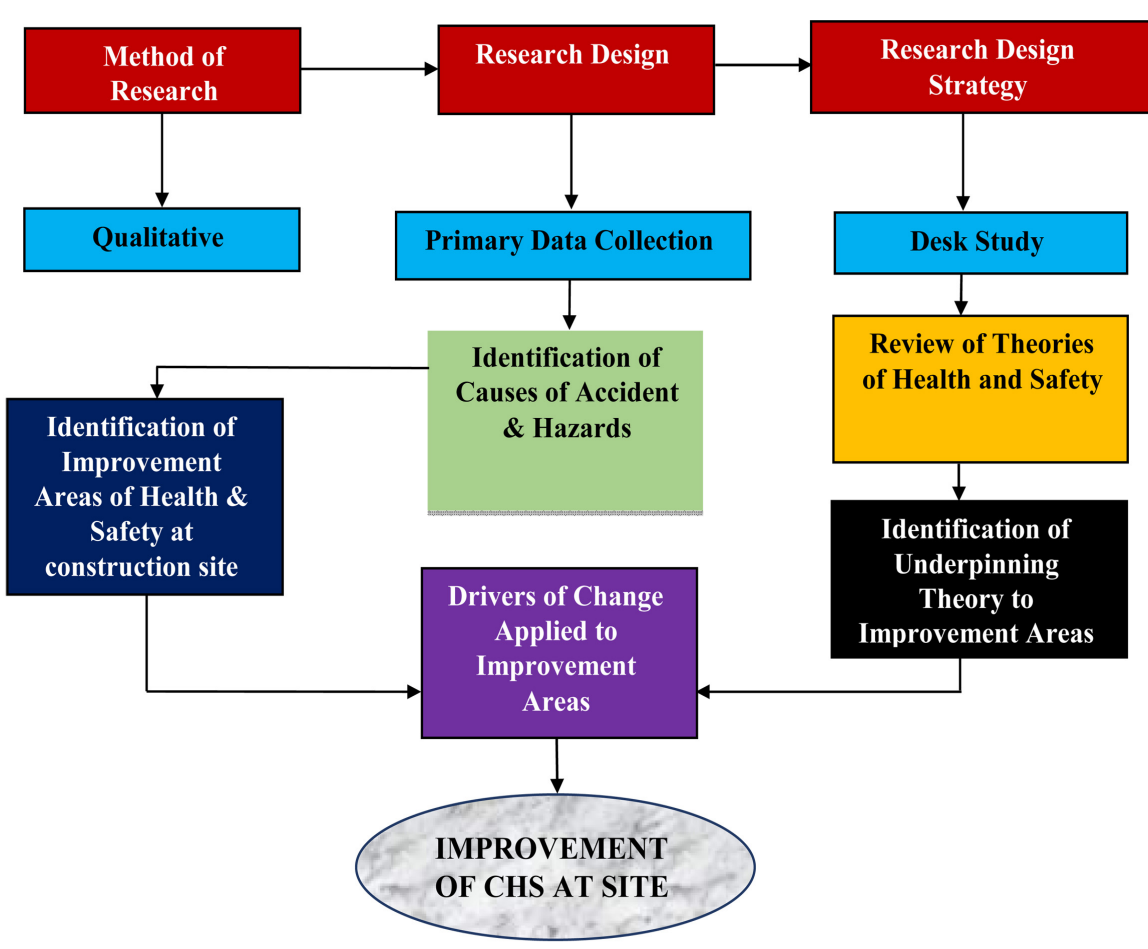

Figure 2. Research flow of study. Construct: authors. 
The qualitative data was analyzed using content analysis to identify the causes of accidents and hazards. A Pareto plot was used to identify the critical causes of accidents and hazards, and for the identification of the issues requiring remedying.

\section{Review of Health and Safety Theories}

In this study, the multi-theory approach was adopted to understand the problems involved in construction health and safety. Theories of Health and Safety were therefore reviewed to identify relevant theories that could contribute to the understanding of the issues of construction health and safety and their improvement on site.

\subsection{Evolution of Theories of Accident Causation}

Conceptual models coupled with common themes have been developed in the past to understand the accident phenomenon [30]. These can be traced to: simple linear models, complex linear models, and complex non-linear models [5].

\subsubsection{Simple Linear Models (SLM)}

The simple linear models (SLM) assume accidents to result from a series of events or circumstances which interact linearly with each other such that accidents can be prevented by eliminating at least one of the causes in the linear sequence [5]. It is essential in accident prevention to identify the root cause(s), eliminate and or place barriers to prevent the cause(s).

\subsubsection{Complex Linear Models (CLM)}

Complex linear models (CLM) assume accidents to result from a combination of unsafe acts and hidden hazard conditions within a system which follow a linear path. The causes of accident may be attributed to actions of the organization, environment and where human beings interact closest to the accident. The model assumes that accidents can be prevented by focusing on strengthening barriers and defenses [5].

\subsubsection{Complex Non-Linear Models (CNLM)}

The CNLM model relates to the emerging understanding that accident models must be non-linear [5]. Accidents, according to the model, may result from combinations of interactions among players within an environment. The model is based on the new thinking that accidents can be prevented only through the understanding of multiple factors affecting the combination and interaction of the players and the environment [5].

\subsection{Theoretical Review of Underpinning Theories/Models}

According to Mensah et al. [31], a theoretical framework is developed based on theoretical review of the research. Although the theories may not be perfect for explaining every accident in detail, they may explain what usually happens, and address the most likely common underlying causes of accidents [32]. According 
to DeCamp and Herskovitz [8], a particular theory of accident explains portion of accidents and not all aspects of the accident. The theories are themselves incomplete in attempting to prevent accidents. It is therefore important to recognize that in accident prevention, all possible causes must be addressed [32]. It is not enough to focus on only one or two theories in accident prevention expedition.

The theoretical review of the research exposed six Theories of Health and Safety as useful to enhance the understanding of the issues involved in accident causation and the improvement of health and safety at the construction site. Together with technological advances in safety and communication, accident causation theory and accident prevention are more advanced than ever [33]. Understanding and quantifying causation will lead to a more scientific approach and greater cost-effective intervention strategies.

\subsection{The Expositions of the Theories of Health and Safety}

The health and safety theories considered suitable for underpinning this study are Behavior Theory of Safety (BTS), comprising the Behavior-Based Safety Theory and Attitude, Behavior and Conditions (ABC) Theory of Safety; Heinrich's Domino Theory of Safety (HDTS); Energy Release Theory of Safety (ERTS), also known as Dr. William Haddon's Theory; Systems Theory of Safety (STS)/Reason's Swiss Cheese Model; Epidemiological Theory (ET); and Human Factor Theory of Safety (HFTS) which includes Accident/Incident Theory. These six theories were selected due to their relevance to the management of health and safety at site.

\subsubsection{The Behavior Theory of Safety}

The theory referred to as Behavior-Based Safety (BBS) Theory is sometimes known as Attitude, Behavior and Conditions (ABC) Theory of Safety. It is a simple sequential linear accident theory/model. Geller [34] believed in seven basic principles (Figure 3): intervention, identification of internal factors, motivation to behave in the desired manner, focus on the positive consequences of appropriate behavior, application of the scientific method, integration of information, and planned interventions [34]. The behavior of employee in workplace safety has been identified as one of the greatest determinants in causes of accident [32], especially as employees interact among a host of varying safety issues. The human behavior thus plays a huge role in a task performed by an employee [34]. The task can have a negative and positive impact or be connected to the person doing the specified task [34] [32]. According to Geller [34], managers, in improving safety performance among employees, must identify the external factors that influence the understanding and improves the employee's behavior.

The BBS Theory indicates that to prevent accidents on site, there is the need to identify the internal factors of behavior of stakeholders, especially the construction worker. The approach of identification must be through the application of scientific method. The focus of such identification should be on the positive consequences of the identified behavior. Appropriate and planned 


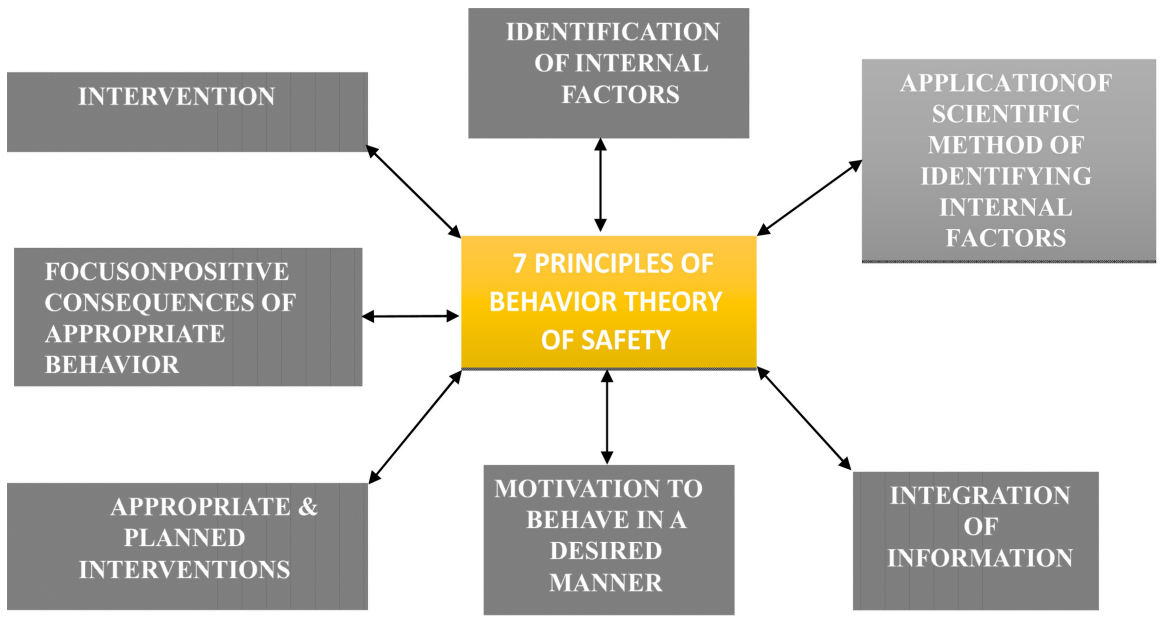

Figure 3. Seven (7) principles of behavior theory of safety. Construct: authors.

interventions are the tool to unearth a person's potential, and principles guiding motivation to behave in the desired manner are to be applied. The negative behavior that are likely to contribute to accidents and hazards are to be eliminated. The environmental conditions likely to produce positive results should be promoted at the construction site, and those that will lead to accidents and hazards eliminated. The underlining principle in this theory is to integrate information to create awareness of these factors among stakeholders.

The Attitude, Behavior and Conditions (ABC) Theory of Safety is therefore a framework for understanding and analyzing behavior, and for developing interventions to improve behavior. Another issue which contributes potentially to employee ill health and must be prevented, is negative workplace behavior such as workplace bullying, which is a work-related psychosocial hazard [34].

\subsubsection{The Heinrich's Domino Theory of Safety}

The Heinrich's Domino Theory is one of the simple sequential linear accident models. It is based on the sequence of events that leads to an incident. The following axioms [35] have been identified in the sequence of accident events also referred to as dominos: the potential injury only occurs as a result of an injury called "Final Domino"; an accident only happens as a result of personal or mechanical hazard; hazards only occur as a result of people's faults; faults of people are inherited, born, bred and educated. The theory postulates that, by removal of any of the events likely to cause accident (an optical domino cause), the effect of the flow of events will not lead to accident. The removal is done through training the staff and to make them aware of danger in the workplace [35]. Heinrich [35] is most famous for originating the concept of the "safety pyramid" and the "five domino model" of accident causation. The latter is a sequential accident model which has been influential on occupational safety thinking. The "domino theory" represents an accident sequence as a causal chain of events, represented as dominos that topple in a chain reaction. The fall of the first domino leads to the fall of the second, followed by the third, and so on until the entire row is 
toppled. According to Heinrich, when the occurrence of a "preventable injury" is identified from the culmination of a series of events, and this series is interrupted by the elimination of even one of the several factors that comprise it, the injury will not occur.

The five factors identified in Heinrich's model were: domino 1: ancestry and the worker's social environment, which impact the worker's skills, beliefs and "traits of character"; domino 2: the worker's carelessness or personal faults, which leads him to pay insufficient attention to the task; domino 3: an unsafe act or a mechanical/physical hazard, such as a worker error; domino 4: the accident; domino 5: injuries or loss, the consequences of the accident.

According to Heinrich [35] the responsibility of accident prevention lies, first, with the employer. He stresses that a truly safety-conscious manager representing the employer, will ensure that his subordinates do as they are instructed. The manager will always exercise his prerogative and obtain compliance, follow through and see the unsafe conditions eliminated. Heinrich recommended strict supervision, remedial training, and discipline as remedy for non-compliance. From the Heinrich's Domino Theory principles, ten steps are involved in identifying causes and preventive measures of accidents and hazards. The Domino theory postulates that 1 ) the background of causes of accident may be due to the fault, errors, or carelessness of the person. 2) It requires the supervisor to strategically train, provide information and effectively supervise the worker to prevent any unsafe act. It also requires 3) management commitment to providing environment of zero build-up of energy of unsafe act, and to ensure that 4) policies for best quality practices and productivity standards are provided. To prevent 5) unsafe act from causing accidents and hazards, 6) corrective actions and 7) preventive acts are to be employed. Accident and hazard usually have 8) hidden effects and 9) indirect cost which eventually lead to 10) injury and its associated direct cost.

It is believed that any safety programs considering the 10 axioms will influence accident prevention [36]. In short, injuries are caused by preceding factors and by removing the unsafe act or hazardous condition, the effect of the factors may be neutralized, and the accidents/injuries are prevented [37].

\subsubsection{Energy Release Theory of Safety}

Energy release theory was developed by Dr William Haddon to identify, classify and prevent damages caused by accidents. It is one of the complex linear models. Haddon's Theory provides that the transfer of energy coupled with relevant force that may cause body injury and property damage is the cause of accidents. According to the theory, the chain of accident-causing events may be disorganized or suppressed by a strategy. Three strategies have been identified as 1) control and prevention of buildup of energy likely to cause injury; 2) creation of an unconducive environment for the buildup of injurious energy; and 3) production of measures to serve as counteractive to buildup of injurious energy (Figure 4). Haddon's theory therefore attempts to deal with prevention of damages 


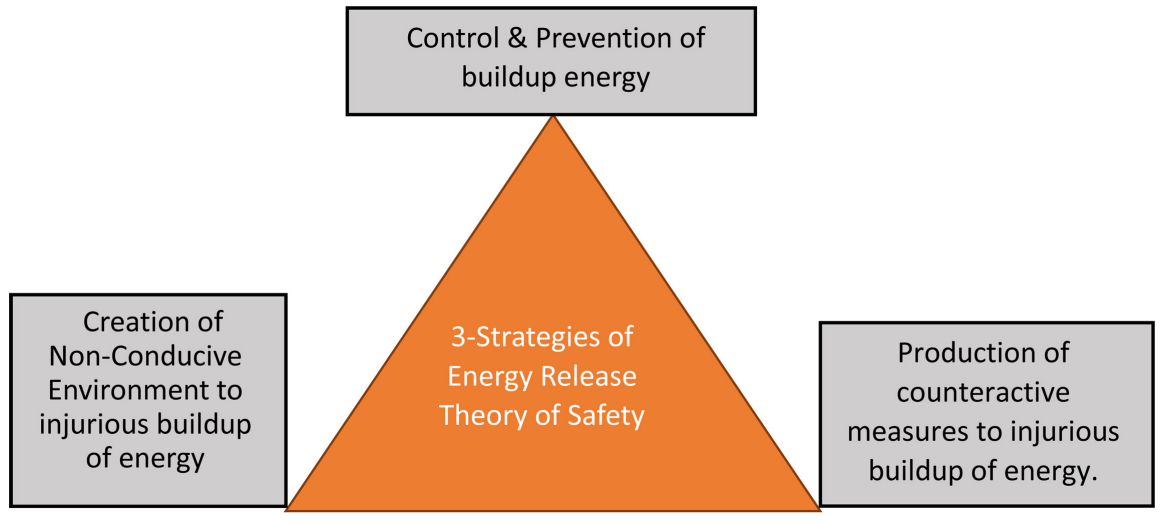

Figure 4. Three strategies of energy release theory of safety.

caused by accidents, and strategies to disorganize or suppress the chain of accident events likely to cause injury.

The concept of energy damage is attributed to Gibson [38]. However, Viner [39] attributes the concept to the discussions between Gibson, Haddon and others. The basis of the model is that the intensity of the incident energy at the point of contact with the recipient may exceed the recipient's damage threshold, resulting in an accident ([39], $\mathrm{p} 42)$.

\subsubsection{Systems Theory of Safety}

Systems Theory is a complex linear model. Over the decades, in scientific description and explanation of natural phenomena, the concept of system has been used. A system is a set of objects and the relationships between the objects and their attributes [40]. In a typical system, the set of all objects whose change in attributes affect the said system and those objects whose characteristics are varied by the conduct of the system is the environment [41].

In the view of DeCamp and Herskovitz [8], much attention has been given to human errors and environmental deficiencies by most of the theories of safety. The systems theory however, focuses differently on the relationship between human and environments. Instead of considering persons to be prone to error, and environment to be full of hazards, a system theory focuses on the harmony between man, machine, and the environment [8]. The occurrence of accidents under normal sense is extremely low. When the harmony between man, machine and the environment is interrupted or one or two of the three components is disturbed, the relationship between the three components, chances that an accident may occur is high. The systems failures have been identified by systemic accident models as a major cause of accident rather than just human failure [5]. It also recognized that events do not happen in isolation of the systemic environment in which they occur.

The systems theory also examines risk taking by identifying that there is an associated risk when someone chooses to do something [42]. However, an unconscious level of calculation is attached to smaller tasks and associated risks.

James Reason's Swiss Cheese Model is the most famous systems theory on ac- 
cident causation. Originally proposed in 1990, the model considers a potential for failure for every step in a process [43]. The model uses slice of Swiss cheese to represent each layer of defense. The holes in the cheese also are used to represent problems or failures in that defense. According to the model, active and latent types of failures can occur. Whereas active failures are unsafe acts that directly contribute to an accident, latent failures are conditions that exist to lay dormant for a period until they lead to an accident. Lack of a policy that describes how a given work task may be completed, is an example of a latent failure.

Accident occurs when the holes in the cheese line up, and no layer of defense can stop the problem. The problem stops and accident does not occur, when the holes are not in line. For example, the first layer could be the policy that addresses work to be completed. The next layer could be the wearing of personal protective equipment (PPE) by employee to complete the task. Failure of PPE policy, or specifying the defective PPE, will lead the problem to pass the line of defense and through the first hole. Again, where there is a policy and employee failed to wear the PPE, or wears the defective PPE as described in the policy, the problem will certainly pass through the next hole. Assuming there are no additional layers of defense, these conditions will allow an accident to happen. Further, when successive layers have been provided and yet small holes exist in them, the problems can still pass through them, making the layers ineffective. The accidents may be prevented when effective safety training and improved knowledge and awareness of possible accident-prone environment have been created [8].

\subsubsection{Epidemiological Theory of Safety}

The Epidemiological Theory of Safety (ETS) is one of the complex linear models. Epidemiological accident models can be traced back to the study of disease epidemics and the search for causal factors around their development. Gordon [44] recognized that injuries, like disease, are equally susceptible to this approach, meaning that our understanding of accidents would benefit by recognizing that accidents are caused by: a combination of forces from at least three sources, which are Host, Agent and Environment. In the causation of accident, man, who has a principal interest is described as the host. The agent could be any means the host or man uses to interfere with the environment. This may be another man, equipment, appliance and any material or chemical used by the host. The environment is the place or system within which the host and the agent find themselves. When the environment is unsupportive, an accident may occur. In his contribution to epidemiological accident modelling, Benner [45] moved away from identifying a few causal factors to understanding how multiple factors within a system combined. In every working environment, the activities of the human being and the equipment or tools they use may cause injury when the activities interact with the environment in a manner that accident may results. The work system resists accidents when the environment is provided with sys- 
tems that are able to monitor and control any changes against the interaction of the host and agent [46]. Thus, the gaps in the work system need to be identified, and filled with the required resources. This will improve the working conditions against accidents and hazards.

\subsubsection{Human Factor Safety Theory (Ferrell's Human Factor Model)}

According to the World Health Organization [47], human factors refer to environmental, organizational and job factors, and human and individual characteristics which influence behavior at work in a way which can affect health and safety. These factors include several specific elements such as, 1) Tasks, workload, and work patterns; 2) Working environment and workplace design; 3) Workplace culture and communication; 4) Leadership and resources; 5) Policies, programs, and procedures; 6) Worker competency and skill; and 7) Employee attitude, personality, and risk tolerance [35]. The elements of human factor theory are illustrated in Figure 5.

Ferrell's model which focuses on multiple causes and specific about the causes is distinguished from Heinrich who considers accidents with single chain reaction [35].

Again, Ferrell considers accidents as the result of one human error. Overload, incompatibility and improper activities are the causes of accidents [36]; [8]. Each of these is a broad category that contains several more specific causes. Improper activities are perhaps the simplest of the concepts, as it involves two straightforward sources of accidents [36]; [8]. First, it is possible that the responsible person simply did not know any better, and second, that the person may have known that an accident may result from an action, but deliberately chose to take

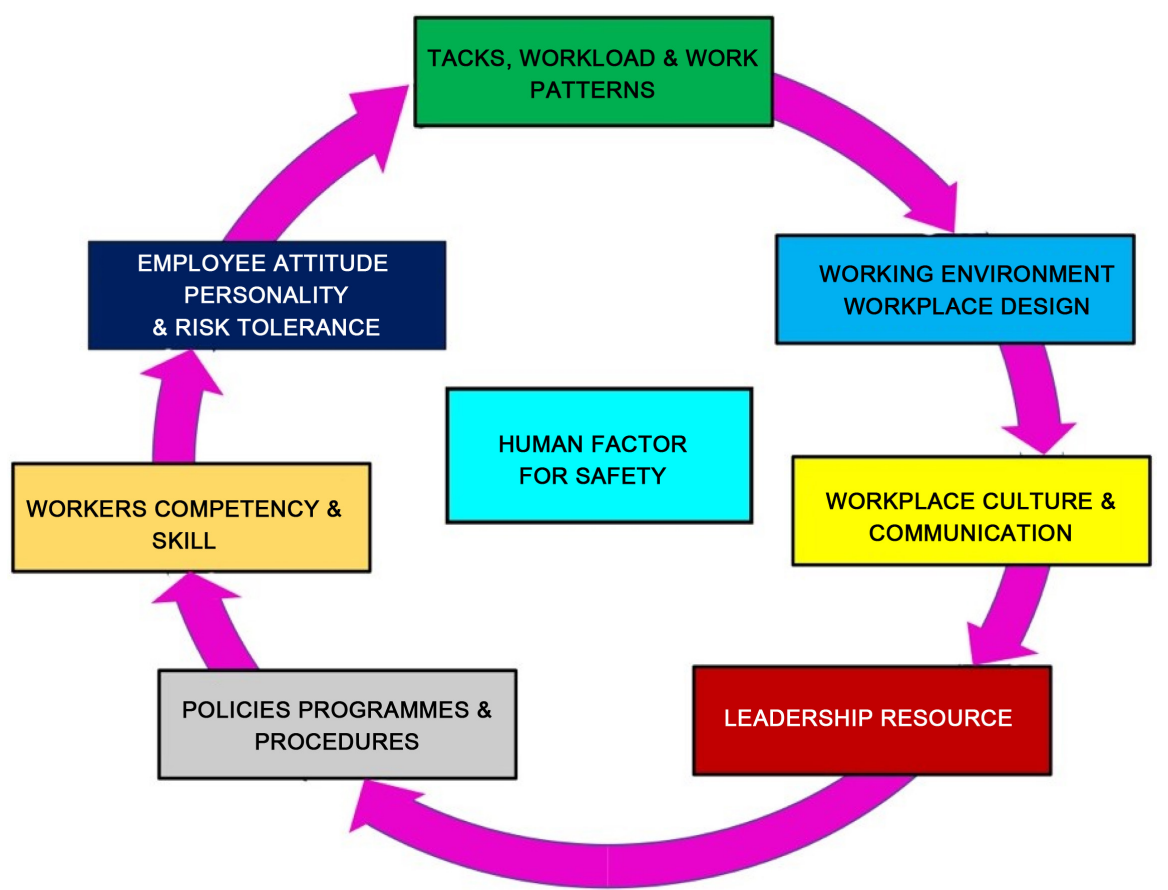

Figure 5. Elements of human factor safety. 
that risk. According to Ferrell [36] and DeCamp and Herskovitz [8], the incompatibility cause is slightly more complex than improper activities. It involves both an incorrect response to a situation by an individual, as well as subtle environmental characteristics such as a workstation that is incorrectly sized.

The overload cause, which is the most complex of Ferrell's causes, can further be broken down into three sub-categories [36]; [8] as the emotional state of the individual, capacity and situational factors. The emotional state of the individual includes conditions relating unmotivated and agitated. The capacity, refers to the individual's physical and educational background, physical fitness, training, and even genetics. The situational factors also include exposure to drugs and pollutants, job related stressors and pressures which also affect one's capacity. Stress and pressure include the difficulty and dangerous level of the task and, the negative or positive effects of the environment-noise, distractions, among others. The human error may result from the three causes of accident overload, incompatibility, and improper activities [8].

Petersen's Accident/Incident theory is largely an extension of Ferrell's Human Factor Theory [35] to include new elements to ensure health and safety at the work place such as, Ergonomic traps which are incompatible work stations, tools or expectations (management failure); Decision to err which results from unconscious or conscious desire to err (personal failure); and Systems failure or Management failure (policy, training, etc.) [36]. A logical decision due to the situation, an unconscious desire to err (psychological failings), and perception of low probability of an accident occurring are reasons for people's choice to err, according to Petersen. These include both actual instances of an unlikely accident, as well as the natural inclination of a person to disregard his or her own mortality [8].

The fact that everyone in the workplace is indeed "only human," means that they are fallible. It is only by understanding human factors, that an occupational safety professional seeks out ways to mitigate risk with stopgap measures that prevent accidents before they occur [36].

No dangers can be fully eliminated from a workplace, but proper education can go a long way to mitigate risk. Initial safety training is a standard practice for most organizations. Unfortunately, safety manuals and curriculum can be quickly outdated. The principles of maintaining a safe workplace begin at the top. It is the responsibility of the executive leadership team to create a zero-tolerance culture that is embraced at all levels of the organization. The mandate to work safely should therefore not be compromised.

\section{Development of the Framework}

The content analysis identified eight causes of accidents and hazards as: 1) Low level of education, 2) Bad attitude towards work, 3) Lack of Appropriate Skills, 4) Lack of communication among stakeholders, 5) Poor Working conditions and environment, 6) Inadequate Equipment and Tools, 7) Lack of Health and 
Safety training among stakeholders and 8) Tiredness of Workers. The pareto plot identified the critical causes of accidents and hazards, and for the identification of the issues requiring remedying. Figure 6 shows five major causes of accidents and hazards that were found critical for remedying as: Inadequate Equipment and Tools, Lack of Health and Safety training among stakeholders; Lack of Appropriate Skills; Poor attitude towards work; and Poor Working conditions and environment. These critical factors had scores of $20 \%, 18.75 \%$, $16.25 \%, 12.5 \%$ and $11.25 \%$ respectively. The critical factors together formed $78.75 \%$ of the contribution of all the eight factors identified by the interviewees. The five critical factors identified from the qualitative study were similar to those identified from the literature except Interrelationship between stakeholders in ensuring construction health and safety, and Sanctions, Motivations and Compensation.

The five critical areas identified in the qualitative study to require improvement were matched with relevant Theories of Health and Safety identified from the literature for the development of the framework for improving construction health and safety on site (Figure 7). The drivers of change underlying the respective theories of health and safety are expected to help improve or remedy the various critical causes of accidents and hazards. The management of the areas requiring improvement using the identified drivers of change espoused by the identified theories should yield the expected improvement in construction health and safety at the construction site.

The first column in the framework establishes the areas of construction health and safety identified in the qualitative study to require critical improvement as a

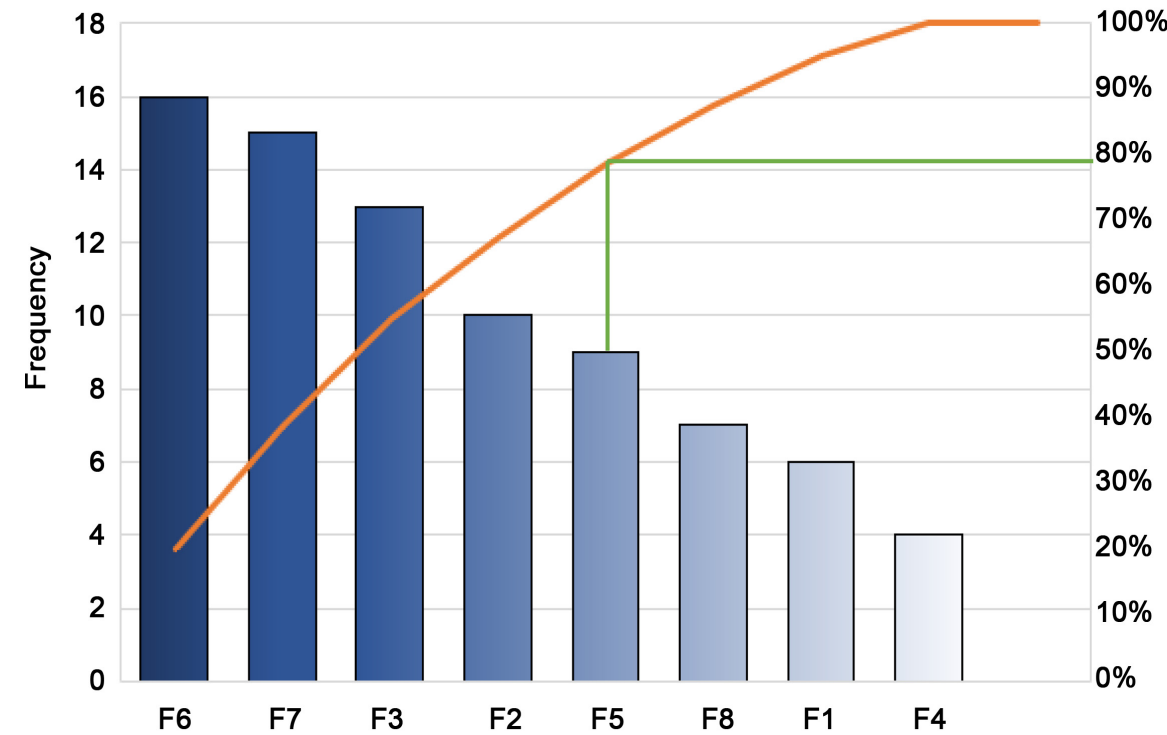

Figure 6. Causes of accidents and hazards in the Ghanaian construction industry. Legend: F1 - Low level of education; F2-Bad attitude to work safety; F3-Lack of appropriate skills; F4-Lack of communication; F5-Poor working conditions and environment; F6-Inadequate equipment and tools; F7-Lack of health and safety training of workers; F8-Tiredness of worker. 


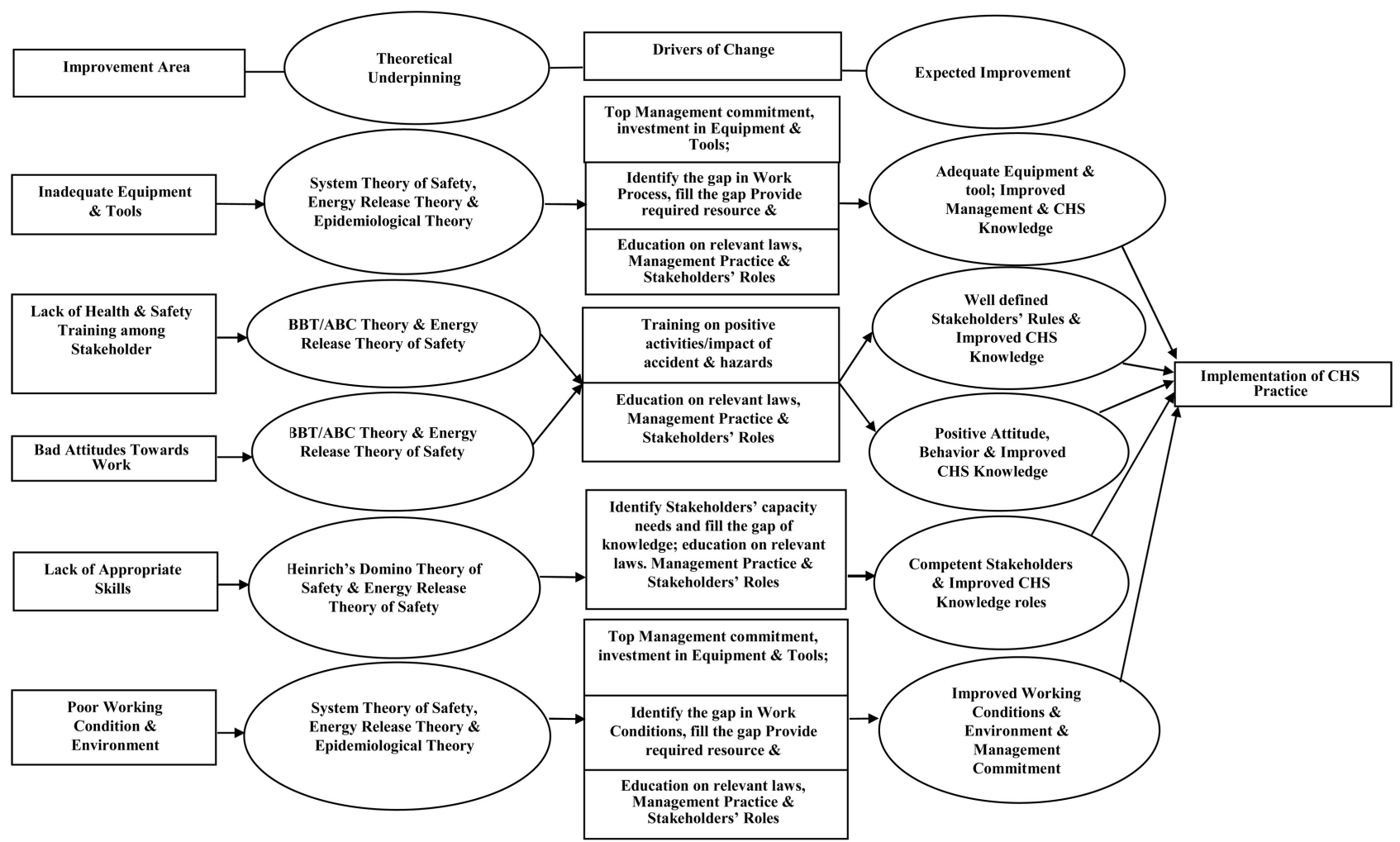

Figure 7. A framework for improving CHS practices on construction sites.

result of the identified causes of accidents and hazards. The second column identifies the selected health and safety theories with the potential to improve the critical areas identified in this study (column 1). The third column identifies the drivers of change underlying the health and safety theories which when applied could result in the expected improvements. The expected improvements in the various areas outlined in the fourth column will work together to achieve an improved construction health and safety with reduced accidents and hazards at the construction site.

The Behavior Theory of Safety (BTS) points to the fact that the behavior and attitude of workers and other stakeholders are the greatest determinants in workplace safety [32]. The BTS underpins the improvement areas numbers 2 and 4 which are Lack of Health and Safety training among stakeholders, and Bad attitude and behavior towards work. When the principle of BTS is applied, it will drive the introduction of education and training of the workers and other stakeholders on positive attitude and behavior, and reduce accidents and hazards, leading to improvement in construction health and safety on site. Human error has been identified by most theories and models to be always a possible cause of accidents. Training of employees carefully and continually is therefore an effective strategy to prevent accidents. An effective and better safety training, and improved awareness and knowledge of possible dangers can decrease the chance of an accident occurring [8].

The Heinrich's Domino Theory of Safety (HDTS) indicates that the removal 
of an optical domino cause prevents accident [35]. Applying the HDTS to underpin the improvement area number 3 i.e., Lack of Appropriate Skill, will drive the introduction of education and training of the workers and remove any deficiency in a worker likely to cause accident, leading to the expected improvement of construction health and safety on site.

The System Theory of Safety (STS) provides that accidents arise from interactions among humans, machines, and environment [41]. The STS underpins the improvement areas numbers 1 and 5, i.e., Inadequate Tools and Equipment, and Poor Working Conditions and Environment. Applying the STS will trigger change in top management commitment to construction health and safety, causing investment in equipment and tools, and environmental issues. Some of the strategies to prevent accidents include safety awareness program, frequent meetings and positive safety posters of an awareness program. This will result in safe workplace and improve construction health and safety practices on site.

The Energy Release Theory of Safety (ERTS) underpins all the areas and adopts strategies that can disorganize or suppress the chain of accident-causing event. Educating stakeholders on their respective roles in ensuring construction health and safety on site, improving working conditions as well as skills training will lead to improved knowledge on how to prevent damage caused by accidents. This will provide strategies which can disorganize or suppress the chain of accident-causing injuries, and reduces accidents and hazards. According to DeCamp and Herskovitz [8], other causes of accident are socialization and sub-culture, which underpin the importance for frequent training and safety programs. Other employees are affected by the behavior of an unsafe employee and this further increases the risk of causing an accident and make the problem grow exponentially.

The improvement of work system, i.e., improvement areas numbers 1 and 5, are also underpinned by the epidemiological theory. Applying the theory will identify gaps in the work process, and appropriate steps taken to fill the gap including the provision of required resources, leading to improved site working conditions for implementation of better construction health and safety practices. The physical environment is an important aspect of accident causation that must be addressed. According to DeCamp and Herskovitz [8], in addition to obvious implications (guard rails, safety warnings, hardhats, etc.), the subtle relationships between man and the environment must also be considered.

Ergonomic designs, to prevent stress and boredom but to increase productivity, can also increase a worker's comfort and decrease the risk of accident causation [8].

DeCamp and Herskovitz [8] suggested the adoption of the Motivator-Hygiene theory (two-factor theory of motivation) [46], to expose employees to motivators such as positive rewards and hygiene factors including routine good working environment. The area of motivation, compensation and sanctions was, however, not identified as an improvement area under the study. According to World Health Organization [47], there are some job factors that result in satisfaction 
while there are others that prevent dissatisfaction. The new trend is offering incentives and rewards to safety-oriented workers. DeCamp and Herskovitz [8] have recommended that managers of construction sites should appreciate and understand the importance of maintaining a positive subculture. They must focus on training and arming themselves to counteract problem employees. They must show keen interest in the safety program errors that cause accidents [36]. Applying the Human Factor Theory will create mutual respect and reasonable duty of care to one another, leading to well-defined roles and responsibilities of stakeholders, resulting in improved construction health and safety practices on site.

\section{Conclusion}

The qualitative study and the theoretical review in this paper have yielded a framework that conceptualizes knowledge and capabilities relevant to the improvement of construction health and safety at site. The use of the underpinning theories coupled with the application of the identified drivers of change is expected to result in improvement of construction health and safety on site, and thereby reduce accidents and hazards. The five (5) expected improvements: positive attitude and behavior; competent stakeholders; improved working conditions and environment and improved management commitment to construction health and safety; improved construction health and safety knowledge; and adequate equipment and tools should work together to provide improved construction health and safety on the construction site. This framework should enable construction stakeholders to easily identify problem areas on site and apply the required improvement measures to create a healthier and safer construction site. This paper also contributes to the use of theories to advance studies on improving health and safety at construction sites, especially in developing countries like Ghana, where such studies have so far attracted little attention. The study provides useful knowledge to improve construction health and safety and reduce site accidents and hazards, and also provides a multi-theory approach for understanding the dynamics of the complexity of the problems involved in construction health and safety.

\section{Acknowledgements}

The authors acknowledge the immense contribution of the originators of the six theories of health and safety reviewed in this article, and to all who contributed to the data collection.

\section{Conflicts of Interest}

The authors declare no conflict of interest regarding the publication of this paper.

\section{References}

[1] Chan, A.P.C., Wong, F.K.W., Yam, M.C.H., Chan, D.W.M., Hon, C.K.H., Dingsdag, 
D. and Biggs, H. (2009) A Research Framework to Improve Construction Safety in the Repair, Maintenance, Minor Alteration, and Addition (RMAA) Sector. Proceedings of the Fifth International Structural Engineering and Construction Conference, Las Vegas, 21-27 September 2009, 771-776.

[2] Ghana Statistical Service (2020) Rebased 2013-2019 Annual Gross Domestic Product. Accra.

[3] Ministry of Finance (2019) The Budget Statement and Economic Policy of the of Ghana for the 2020 Financial Year. http://www.mofep.gov.gh

[4] Ghana Investment Promotion Centre (GIPC) (2006) Ghana Investment Profile: Property Development. Ghana Investment Promotion Centre (GIPC), Accra.

[5] Hollnagel, E. (2010) FRAM Background. http://sites.google.com/site/erikhollnagel2/coursematerials/FRAM background.pdf

[6] Stranks, J. (1990) A Manager's Guide to Health and Safety at Work. Kogan Page, London.

[7] Jeong, B.Y. (1998) Occupational Deaths and Injuries in the Construction Industry. Applied Ergonomics, 29, 355-360. https://doi.org/10.1016/S0003-6870(97)00077-X

[8] DeCamp, W. and Herskovitz, K. (2015) The Theories of Accident Causation. In: Security Supervision and Management, Butterworth-Heinemann, Oxford, 71-78. https://doi.org/10.1016/B978-0-12-800113-4.00005-5

[9] International Labour Organization (ILO) (2003) Safety in Numbers: Pointers for a Global Safety Culture at Work. Geneva.

[10] Asanka, W.A. and Ranasinghe, M. (2015) Study on the Impact of Accidents on Construction Projects. 6 th International Conference on Structural Engineering and Construction Management, Kandy, 11-13 December 2015, 58-67.

[11] Ghana Statistical Service, GSS (2016) 2015 Labor Force Report. Ghana Statistical Service, Accra.

[12] Ghana Statistical Service, GSS (2015) 2014 Annual Report, September Edition. Ghana Statistical Service, Accra.

[13] Hämäläinen, P., Takala, J. and Saarela, K.L. (2006) Global Estimates of Occupational Accidents. Safety Science, 44, 137-156. https://doi.org/10.1016/j.ssci.2005.08.017

[14] Hughes, P. and Ferrett, E. (2013) International Health and Safety at Work: The Handbook for the NEBOSH International General Certificate. Routledge, London. https://doi.org/10.4324/9780203096291

[15] Ramachandran, P.N. (2011) Emergency Preparedness-An Action Plan for Industries.

[16] Health and Safety Executive (HSE) (2003) Successful Health and Safety Management. HMSO, London.

[17] Wong, F.K., Chan, A.P., Yam, M.C., Wong, E.Y., Kenny, T.C., Yip, K.K. and Cheung, E. (2009) Findings from a Research Study of Construction Safety in Hong Kong. Journal of Engineering, Design and Technology, 7, 130. https://doi.org/10.1108/17260530910974952

[18] Huang, X. and Hinze, J. (2003) Analysis of Construction Worker Fall Accidents. Journal of Construction Engineering and Management, 129, 262-271. https://doi.org/10.1061/(ASCE)0733-9364(2003)129:3(262)

[19] Holt, A.S.J. (2008) Principles of Construction Safety. John Wiley and Sons, Hoboken.

[20] OHS Body of Knowledge (2012) Biological Hazards. OHS Body of Knowledge. 
[21] European Statistics on Accidents at Work (ESAW) (2003) Eurostat.

[22] Mwakali, J. (2006) Proceedings from the International Conference on Advances in Engineering and Technology (AET2006). Elsevier, Amsterdam.

[23] Li, R.Y.M. and Poon, S.W. (2013) Construction Safety. Springer Science \& Business Media, Berlin.

[24] Abdelhamid, T.S. and Everett, J.G. (2000) Identifying Root Causes of Construction Accidents. Journal of Construction Engineering and Management, 126, 52-60. https://doi.org/10.1061/(ASCE)0733-9364(2000)126:1(52)

[25] Construction Workers Research Group (1998) A Multi-Centre Cross-Sectional Survey on Safety at Construction Sites in Thailand 1994-1995. Journal of Occupational Health, 40, 319-324. https://doi.org/10.1539/joh.40.319

[26] Laryea, S. and Sarfo, M. (2010) Health and Safety on Construction Sites in Ghana. The Construction, Building and Real Estate Research Conference of the Royal Institution of Chartered Surveyors, Dauphine Université, Paris, France, 2-3 September 2010.

[27] Eyiah, A.K., Kheni, N.A. and Quartey, P.D. (2019) An Assessment of Occupational Health and Safety Regulations in Ghana: A Study of the Construction Industry. Journal of Building Construction and Planning Research, 7, 11-31. https://doi.org/10.4236/jbcpr.2019.72002

[28] Flick, U. (2006) An Introduction to Qualitative Research. Sage, London.

[29] Gay, D.A., Morgan, F.D., Vichabian, Y., Sogade, J.A., Reppert, P. and Wharton, A.E. (2006) Investigations of Andesitic Volcanic Debris Terrains: Part 2-Geotechnical. Geophysics, 71, B9-B15. https://doi.org/10.1190/1.2159046

[30] Health and Safety Professionals Alliance (HaSPA) (2012) The Core Body of Knowledge for Generalist OHS Professionals. Safety Institute of Australia, Tullamarine.

[31] Mensah, S., Ayarkwa, J. and Nani, G. (2020) A Theoretical Framework for Conceptualizing Contractors' Adaptation to Environmentally Sustainable Construction. International Journal of Construction Management, 20, 801-811. https://doi.org/10.1080/15623599.2018.1484860

[32] Wijne, M. (2018) Health and Safety Theories; British Safety Services; June 2018.

[33] Bureau of Labor Statistics (2013) Employer-Reported Workplace Injuries and Illnesses 2012. http://www.bls.gov/iif/oshwc/osh/os/ostb3569.pdf

[34] Geller, E.S. (2016) The Psychology of Safety Handbook. CRC Press, Boca Raton. https://doi.org/10.1201/9781420032567

[35] Heinrich, H.W. (1931) Industrial Accident Prevention: A Scientific Approach. McGraw-Hill, New York.

[36] Cleveland State University (CSU) (2017) Theories of Accident Causation. Work Zone Safety and Efficiency Transportation Center. Accident Theories.

[37] Burnham, J.C. (2008) The Syndrome of Accident Proneness (Unfallneigung): Why Psychiatrists Did Not Adopt and Medicalize It. History of Psychiatry, 19, 251-274. https://doi.org/10.1177/0957154X07077594

[38] Gibson, J.J. (1961) The Contribution of Experimental Psychology to the Formulation of the Problem of Safety-A Brief for Basic Research. Behavioral Approaches to Accident Research, 1, 77-89.

[39] Viner, D. (1991) Accident Analysis and Risk Control. VRJ Delphi, Carlton.

[40] Kasianiuk, K. (2020) On a System-Environment Relationship in Scientific Inquiry: A Response to "Definition of System" by AD Hall and RE Fagen. Systems Research 
and Behavioral Science. https://doi.org/10.1002/sres.2681

[41] Hall, A.D. and Fagen, R.E. (1956) Definition of System. General Systems, the Yearbook of the Society for Advancement of General Systems Theory. Vol. 1, The Society, Ann Arbor, 18-28.

[42] Firenze, R.J. (1978) The Process of Hazard Control. Kendall Hunt, New York.

[43] Reason, J. (1990) Human Error. Cambridge University Press, Cambridge. https://doi.org/10.1017/CBO9781139062367

[44] Gordon, J.E. (1949) The Epidemiology of Accidents. American Journal of Public Health and the Nation's Health, 39, 504-515. https://doi.org/10.2105/AJPH.39.4.504

[45] Benner, L. (1975) Accident Investigations: Multilinear Events Sequencing Methods. Journal of Safety Research, 7, 67-73.

[46] Hollnagel, E. (2004) Barriers and Accident Prevention. Ashgate Publishing, Aldershot.

[47] World Health Organization (2009) Human Factors in Patient Safety: Review of Topics and Tools. WHO, Geneva. 